\title{
Foraging economics and performance of polar and subpolar Atlantic seabirds
}

\author{
JOHN P. CROXALL and DIRK R. BRIGGS
}

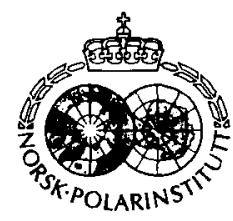

Croxall, J. P. \& Briggs, D. R. 1991: Foraging economics and performance of polar and subpolar Atlantic seabirds. Pp. 561-578 in Sakshaug, E., Hopkins, C. C. E. \& Øritsland, N. A. (eds.): Proceedings of the Pro Mare symposium on Polar Marine Ecology, Trondheim, 12-16 May 1990. Polar Research 10(2).

Seabirds of high latitudes in the North and South Atlantic (chiefly penguins, Procellariformes, alcids, shags, Gannet and Kittiwake) are compared (on absolute and energy-, mass- and time-specific scaled bases) in terms of the rate at which they supply energy to their offspring, the rate of offspring growth, and the duration of the dependence (fledging) period. For a smaller suite of species, time and energy budgets during complete foraging cycles (including time ashore) and while at sea are compared. The broad-scale comparisons show storm petrels to have consistently low provisioning and growth rates, and Kittiwakes, Gannets, shags and some penguins to have consistently high rates. Penguins (except the Gentoo Penguin) and albatrosses spend most of a foraging cycle at sea; murres, shags, gannet and kittiwake spend at least half the time ashore, guarding their offspring. Energy budgets are much more similar, because of the disproportionate cost of at-sea activities, although the time spent flying, swimming, resting, and diving varies widely between species and is often difficult to interpret in terms of active foraging. Other apparent anomalies include the large amount of time Common Murres spend resting at sea and the high resting and low flight metabolic rates of kittiwakes and gannets. Assessments of foraging performance need to be more broadly based than hitherto and to take account of both physical constraints and ecological contexts. Further development of these approaches, especially critical interspecies comparisons, requires better discrimination of activities at sea, measurement of activity-specific energy costs and more accurate data on provisioning rates to offspring, particularly of North Atlantic species, notably Gannets and shags.

John P. Croxall and Dirk R. Briggs, British Antarctic Survey, Natural Environment Research Council. High Cross, Madingley Road, Cambridge, CB3 OET, UK.

\section{Introduction}

The last few years have seen the start of a transformation of the quantitative study of the foraging ecology of pelagic marine animals. From making inferences on the basis of dietary studies and largely anecdotal at-sea observations, we are now able to measure or estimate many aspects of atsea energy and activity budgets. In the case of species which hunt by diving, we can even obtain continuous records of the pattern and profile of their foraging activities. To complement these exciting advances we need to ensure the continuing development of appropriate conceptual frameworks and hypotheses, extending earlier approaches (e.g. Drent \& Daan 1980; Nagy 1987). This requires that relevant data are collected during the on-shore, as well as the at-sea, phases of activity.

As a first step towards these objectives, this paper reviews aspects of the pattern of acquisition and use of energy by a variety of pelagic seabirds (and the Antarctic Fur Seal) of high latitudes in the Atlantic Ocean, during the time of year when they have dependent offspring. Both the above restrictions are important. Pelagic seabirds are likely to be most constrained (certainly spatially and perhaps energetically) when they have to keep returning to their breeding site to feed offspring. They are also easiest to study at this time. Most studies of energy and activity budgets of pelagic seabirds so far have been conducted on species from the polar and subpolar regions of the North and South Atlantic. These two areas have seabird avifaunas of similar size (Table 1), though rather different composition. Pelecaniformes, gulls, and terns are particularly common in the North Atlantic; Procellariformes predominate in the South Atlantic, where penguins and diving-petrels are the ecological equivalents of the alcids of the north.

The general framework adopted is a comparative review of the efficiencies of energy acqui- 
Table I. Composition of seabird avifaunas of high latitudes of North and South Atlantic.

\begin{tabular}{|c|c|c|c|c|c|c|}
\hline & \multicolumn{4}{|c|}{ North Atlantic } & \multicolumn{2}{|c|}{ South Atlantic } \\
\hline & $\begin{array}{l}\text { Svalbard } \\
80^{\circ} \mathrm{N}\end{array}$ & $\begin{array}{l}\text { Norway } \\
65^{\circ}-70^{\circ} \mathrm{N}\end{array}$ & $\begin{array}{l}\text { UK } \\
55^{\circ} \mathrm{N}\end{array}$ & $\begin{array}{l}\text { Antarctica } \\
75^{\circ} \mathrm{S}\end{array}$ & $\begin{array}{l}\text { Peninsula } \\
60-65^{\circ} \mathrm{S}\end{array}$ & $\begin{array}{l}\text { South Georgia } \\
55^{\circ} \mathrm{S}\end{array}$ \\
\hline Penguins & & & & 2 & 2 & 3 \\
\hline Alcids & 5 & 5 & 4 & & & \\
\hline Diving-petreis & & & & & & 2 \\
\hline Albatrosses & & & & & & 4 \\
\hline Petrels & 1 & 1 & 2 & 4 & 5 & 6 \\
\hline Storm-petrels & & 1 & 2 & 1 & 2 & 3 \\
\hline Skuas/Gulls & 4 & 6 & 6 & 1 & 2 & 2 \\
\hline Kittiwake & 1 & 1 & 1 & & & \\
\hline Terns & 1 & 1 & 4 & & 1 & 1 \\
\hline Shags & & 2 & 2 & & 1 & $i$ \\
\hline Gannet & & 1 & 1 & & & \\
\hline Total & 12 & 18 & 22 & 8 & 14 & 22 \\
\hline
\end{tabular}

sition by parents and energy transfer to, and utilisation by, offspring. At a simple level there are three interlinked processes involved here*:

1) Foraging efficiency - the energy required by adults (plus offspring) divided by the energy spent acquiring this (Nagy et al. 1984);

2) Provisioning efficiency - the rate at which power (energy per unit time) is delivered to offspring (Pennycuick et al. 1984);

3) Rearing efficiency - the rate at which offspring become independent.

In this paper we firstly make a broad-scale review of provisioning and rearing efficiency across all available species, seeking to identify general overall patterns and whether any consistent differences exist between the main taxonomic/ecological groups involved (e.g. Procellariformes, Alcidae, Pelecaniformes, etc.). Secondly, for the much smaller number of species for which adequate activity and energy budget data exist, we review foraging costs and efficiencies.

\section{Methods}

\section{Provisioning rate}

The provisioning rate or delivered power, in $\mathrm{W}$,

\footnotetext{
"None of these is actually a true efficiency. Thus 1) while dimensionless does not relate to the conversion of encrgy, 2) has dimensions of $\mathrm{ML}^{2} \mathrm{~T}^{-3}$. and 3) has dimensions of $\mathrm{T}^{-1}$.
}

is defined by $\mathrm{P}=\mathrm{em} / \mathrm{t}$, where $\mathrm{e}$ is the energy density (energy per unit wet mass in $\mathrm{Jg}^{-1}$ ) of the food delivered to each offspring, $m$ is its mass $(\mathrm{g})$, and $t$ is the interval (in $s$ ) between meals. For species where both parents take equal shares in rearing, this can be taken as one-half the duration of the average foraging trip. Provisioning rates are for mid- to full-sized chicks or averaged from the end of the brooding period to fledging, depending on species.

In order to compare species of different size, the relative delivered power $P_{r}$ is calculated. This is the ratio of the delivered power $(P)$ to the adult metabolic power $\left(P_{m}\right)$ : i.e., $P_{r}=P / P_{m}$ (see Pennycuick et al. 1984), $P_{m}$ is defined here using the equation for seabird basal metabolic rate (BMR) developed by Ellis (1984), where BMR $\left(\mathrm{kJd}^{-1}\right)=381.8 \mathrm{M}^{0.721}$ (where $\mathrm{M}$ is in $\mathrm{kg}$ ), and converting this to $\mathrm{W}$ in order that both parts of the ratio have the same units, producing a dimensionless number which has eliminated the effect of adult body mass.

\section{Rearing rate}

Three indices of the rate at which offspring progress towards independence are generally available: fledging (weaning) period, growth (in mass) rate, and growth constant (Ricklefs 1968). None of these is entirely satisfactory. Fledging periods are known to be relatively insensitive to intraspecific changes in energy provisioning (presumably because processes like bone and feather growth proceed at different and more constant 
rates than mass growth) and so may not be a good index of interspecies provisioning differences. Growth rates only apply to the period from near hatching until peak mass is achieved. While this is roughly equivalent to the whole fledging period for most penguins and alcids, Procellariformes and Pelecaniformes attain peak mass after $50-70 \%$ of the fledging period has elapsed and then undergo a period (of variable duration) of weight recession. Growth constants have the additional disadvantages of being available for relatively few seabird species and of being very sensitive to errors in estimated asymptotic mass. Here only fledging periods and growth rates are used. For comparison between species of different mass (because growth rates and fledging periods are not independent of mass), these rates need scaling appropriately. This is achieved, following Pennycuick et al. (1984), by calculating a physiological time unit (ptu) for each species, where the ptu (in s) $=\mathbf{M}^{0.315}$ (where $\mathbf{M}$ is in $\mathrm{kg}$ ). To derive dimensionless values, this time unit is used as the divisor with fledging period(s) and as a multiplier with weight-specific growth rate $\left(\mathrm{g} \cdot \mathrm{g}^{-1} \cdot \mathrm{s}^{-1}\right)$.

The main general sources of data for provisioning and rearing rates are Croxall (1984), Pennycuick et al. (1984), Nettleship \& Birkhead (1985), Croxall et al. (1988a, b), Croxall \& Gaston (1988), and Prince \& Harris (1988).

The main sources for species not covered therein are:

\begin{tabular}{|c|c|}
\hline \multirow{3}{*}{$\begin{array}{l}\text { Manx Shearwater } \\
\text { Northern Fulmar }\end{array}$} & Brooke (1990) \\
\hline & $\begin{array}{l}\text { Cramp \& Simmons } \\
\text { (1977) }\end{array}$ \\
\hline & Furness \& Todd (1984) \\
\hline \multirow[t]{3}{*}{ Black-legged Kittiwake } & $\begin{array}{l}\text { Cramp } \\
(1983)\end{array}$ \& Simmons \\
\hline & Galbraith (1983) \\
\hline & $\begin{array}{l}\text { Barrett \& Runde } \\
\text { (1980) }\end{array}$ \\
\hline \multirow[t]{3}{*}{ Blue-eyed Shag } & Shaw (1984) \\
\hline & $\begin{array}{l}\text { Bernstein \& Maxson } \\
(1984,1985)\end{array}$ \\
\hline & Croxall et al. (1991) \\
\hline \multirow[t]{2}{*}{ Common Shag } & $\begin{array}{l}\text { Cramp \& Simmons } \\
(1977)\end{array}$ \\
\hline & Wanless et al. (1991) \\
\hline Northern Gannet & $\begin{array}{l}\text { Cramp \& Simmons } \\
(1977)\end{array}$ \\
\hline & Nelson (1978) \\
\hline & $\begin{array}{l}\text { Montevecchi \& Porter } \\
\text { (1980). }\end{array}$ \\
\hline
\end{tabular}

Whenever possible, all data for any one species come from the same study.

\section{Foraging activity and energy budgets}

Only for the following twelve species are there sufficient empirical data for adequate analysis:

$\begin{array}{ll}\text { Antarctic Fur Seal } & \text { Croxall et al. (1985) } \\ & \text { Kooyman et al. (1986) } \\ & \text { Costa et al. (1989) } \\ & \text { Boyd \& Croxall } \\ & (1992) \\ \text { Gentoo Penguin } & \text { Davis et al. (1989) } \\ \text { Williams et al. (1992) } \\ \text { Macaroni Penguin } & \text { Davis et al. (1989) } \\ & \text { Croxall et al. } \\ & (1993)\end{array}$

King Penguin

Jackass Penguin

Kooyman et al. (1992)

Little Penguin

Common Murre

Nagy et al. (1984)

Gales et al. (1990)

Gales \& Green (1990)

Cairns et al. (1987)

Cairns et al. (1990)

Burger \& Piatt (1990)

Wandering Albatross

Adams et al. (1986)

Prince \& Morgan

(1987)

Grey-headed Albatross Adams \& Brown

(1984)

Prince \& Francis

(1984)

Blue-eyed Shag

Northern Gannet

Costa \& Prince (1987)

Croxall et al. (1991)

Birt-Friesen et al.

(1989)

and pers. comm.

Black-legged Kittiwake

Gabrielsen et al. (1987)

Gabrielsen \& Mehlum

(1989).

In two cases assumptions or data manipulations additional to those made by the authors cited above were introduced to complete at-sea energy budgets. For Kittiwakes, energy cost of flight was calculated assuming the energy expended on the water was equivalent to resting metabolic rate (RMR) - see Birt-Friesen et al. (1989) for evidence supporting this. For Common Murre, data for field metabolic rates (FMR) from Cairns et al. (1990) were plotted as a function of time spent flying in order to estimate the energy costs of flight in the manner described by Birt-Friesen (1989). 


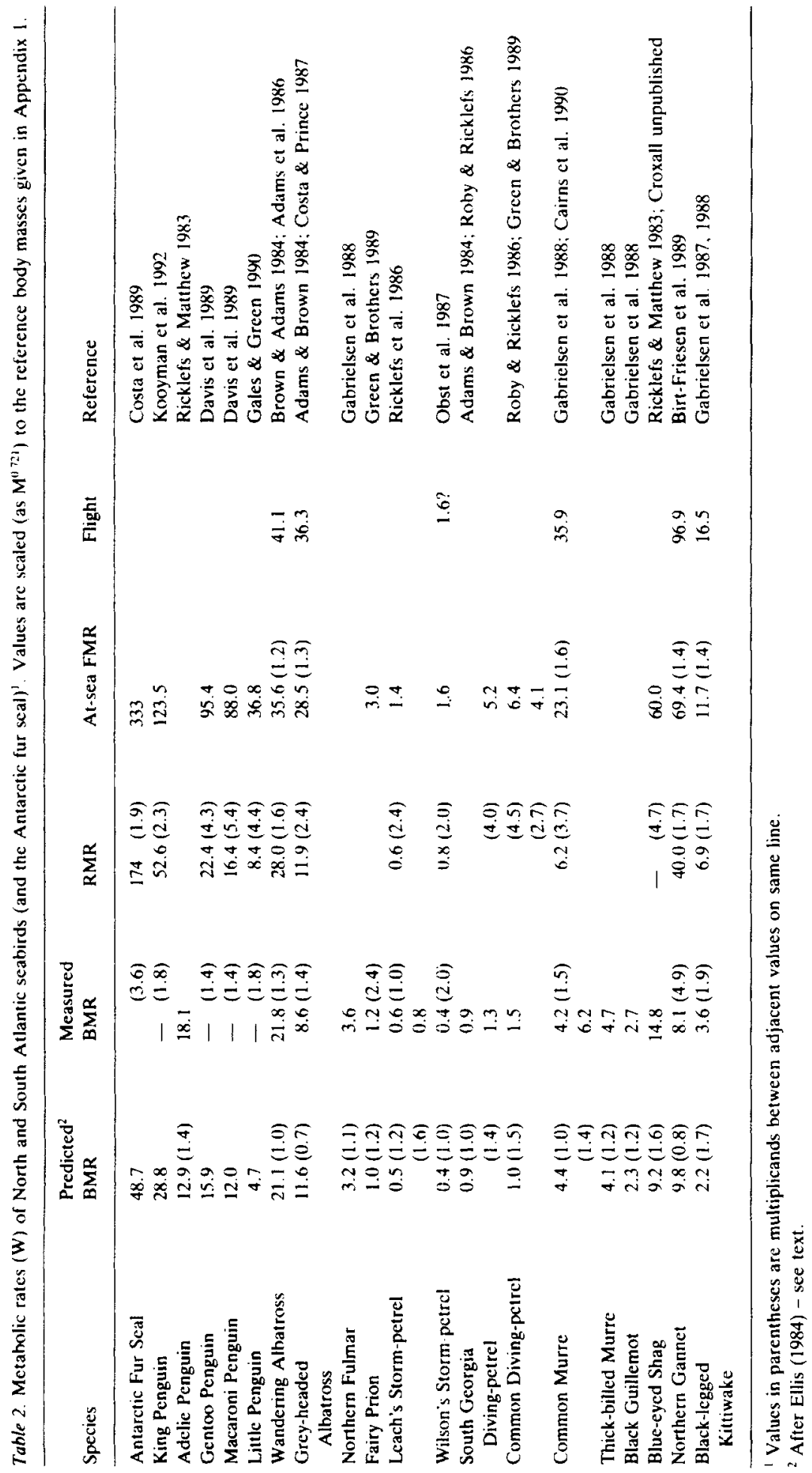


Table 3. Flight and foraging characteristics of the main groups of pelagic seabirds (and the Antarctic fur seal) in the North and South Atlantic.

\begin{tabular}{|c|c|c|c|c|}
\hline Group & $\begin{array}{l}\text { Flight } \\
\text { mode }\end{array}$ & $\begin{array}{c}\text { Forage } \\
\text { mode }\end{array}$ & $\begin{array}{l}\text { Typical } \\
\text { species }\end{array}$ & $\begin{array}{l}\text { Mass } \\
(\mathrm{kg})\end{array}$ \\
\hline Fur seal & Nil & Epipelagic dive & Antarctic Fur Seal & 35 \\
\hline \multirow[t]{3}{*}{ Penguin } & Nil & Epipelagic dive & King Penguin & 13 \\
\hline & & & Gentoo Penguin & 6 \\
\hline & & & Macaroni Penguin & 4 \\
\hline Alcid & Flap & Epipelagic dive & Common Murre & 1 \\
\hline \multirow[t]{2}{*}{ Diving-petrel } & & & Little Auk & 0.16 \\
\hline & & & Common Diving-petrel & 0.13 \\
\hline Albatross & Glide/ & Surface seize & Wandering Albatross & 9 \\
\hline Petrel & Flap-glide & & Grey-headed Albatross & 4 \\
\hline \multirow[t]{3}{*}{ Storm-petrel } & & & Northern Fulmar & 0.7 \\
\hline & & & Wilson's Storm-petrel & 0.04 \\
\hline & & & Leach's Storm-petrel & 0.05 \\
\hline Gull & Flap & Surface seize & Black-legged Kittiwake & 0.04 \\
\hline Gannet & $\begin{array}{l}\text { Flap } \\
\text { (Flap-glide) }\end{array}$ & Plunge dive & Northern Gannet & 3 \\
\hline \multirow[t]{2}{*}{ Shag } & Flap & Benthic dive & Common shag & 2 \\
\hline & & & Blue-eyed Shag & 3 \\
\hline
\end{tabular}

Sources of other data on metabolic rates are referenced in Table 2. The flight and foraging characteristics of the main groups of species under discussion are summarised in Table 3 . The complete database (as used for Figures 1-6) is too large to include here but will be published elsewhere and can be obtained from the author on request. Data for the main species are summarised in Appendices 1 \& 2.

\section{Results}

\section{Provisioning rates}

Larger seabirds deliver power faster than smaller ones but within this broad generalisation there are no clear indications of different relationships for different taxonomic or ecological groups (Fig. 1A). When body size is taken into account, however, certain taxa are particularly distant from the horizontal line between storm-petrels and penguins (Fig. 1B). Thus the Wandering Albatross and medium-sized Pterodroma and Procellaria petrels and their relatives deliver power more slowly than expected. Conversely giant petrels (relatively inshore foragers which time their breeding to coincide with access to energy-rich carrion supplies (Hunter 1983)) and Northern Fulmar deliver power much faster. The three pelecaniform species (shags and Gannet) and the
Kittiwake also have conspicuously higher provisioning rates.

\section{Rearing rates}

Although fledging periods in general are positively correlated with adult body weight (Fig. 2A), there are many anomalies and discrepancies and these are accentuated when the scaled relationship is considered (Fig. 2B). As Croxall \& Gaston (1988) noted, some of these relate to alcid species, such as Uria and Alca whose chicks have intermediate (rather than semi-precocial) development and leave the nest site when only partly grown, and to Emperor Penguins, whose chicks become independent at about $50 \%$ of adult mass. In contrast, King Penguin chicks are reared to $80 \%$ of adult mass during the summer of their birth, fed only intermittently through the winter and then fledged the following summer. Wandering Albatross chicks, which are also reared throughout the winter, similarly take a disproportionately long time to fledge. The most extreme group, however, comprises the stormpetrels, whose fledging periods are longer than petrels 20 times their mass. In general, alcids and penguins have distinctly shorter scaled fledging periods than Procellariformes.

The close relationship between offspring maximum growth rate and adult body mass, extending across four orders of magnitude of mass, is very 

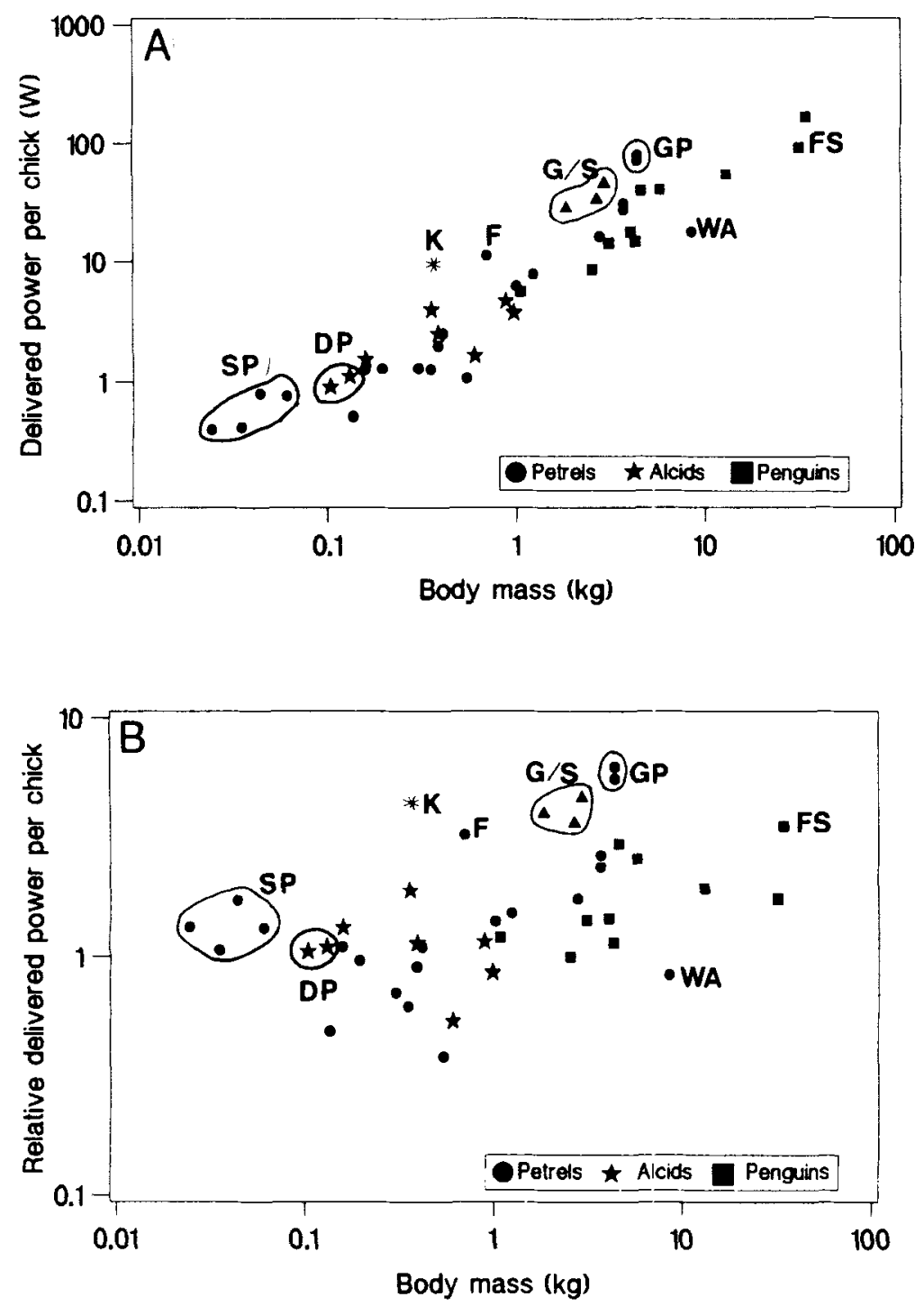

Fig. 1. Relationship between adult body mass and (A) absolute and (B) relative (scaled) rate of energy (power) delivery per chick. Note log-log scale. $\mathrm{DP}=$ diving petrels. $F=$ Northern Fulmar, FS = Antarctic Fur Seal. $\mathrm{G} / \mathrm{S}=$ Northern Gannet and Shags (triangles). $\mathrm{GP}=$ giant petrels. $\mathrm{K}=$ Black-legged Kittiwake. $\mathrm{SP}=$ storm-petrels. $\mathrm{WA}=$ Wandering Albatross.

striking (Fig. 3A). When properly scaled (Fig. $3 B$ ) the main conclusion is that petrels, and especially storm-petrels, show consistently lower growth rates than alcids, pelecaniforms and most penguins.

Despite the much closer relationship between body mass and growth rate than between body mass and fledging period, there is, as expected, a strong inverse relationship between scaled growth rate and scaled fledging period (Fig. 4B). Thus in species whose chicks have high growth rates, fledging periods are short. There is no relationship between the unscaled parameters (Fig. 4A), rein- forcing the importance of using correctly scaled parameters for these kinds of comparisons.

\section{Provisioning: rearing efficiency}

There is a positive overall relationship between the power acquired by a chick and its growth rate (Fig. 5A). A curvilinear, rather than linear, relationship gives the best fit, suggesting that medium-sized species may, in absolute terms, be more efficient than either smaller or larger ones (see p. 574). When appropriately scaled (Fig. 5B), certain differences become more obvious. Thus 
Fig. 2. Relationship between adult body mass and (A) fledging period and (B) scaled fledging period. Note $\log -\log$ scale. $\mathrm{KP}=$ King Penguin. Other conventions as in Fig. 1.
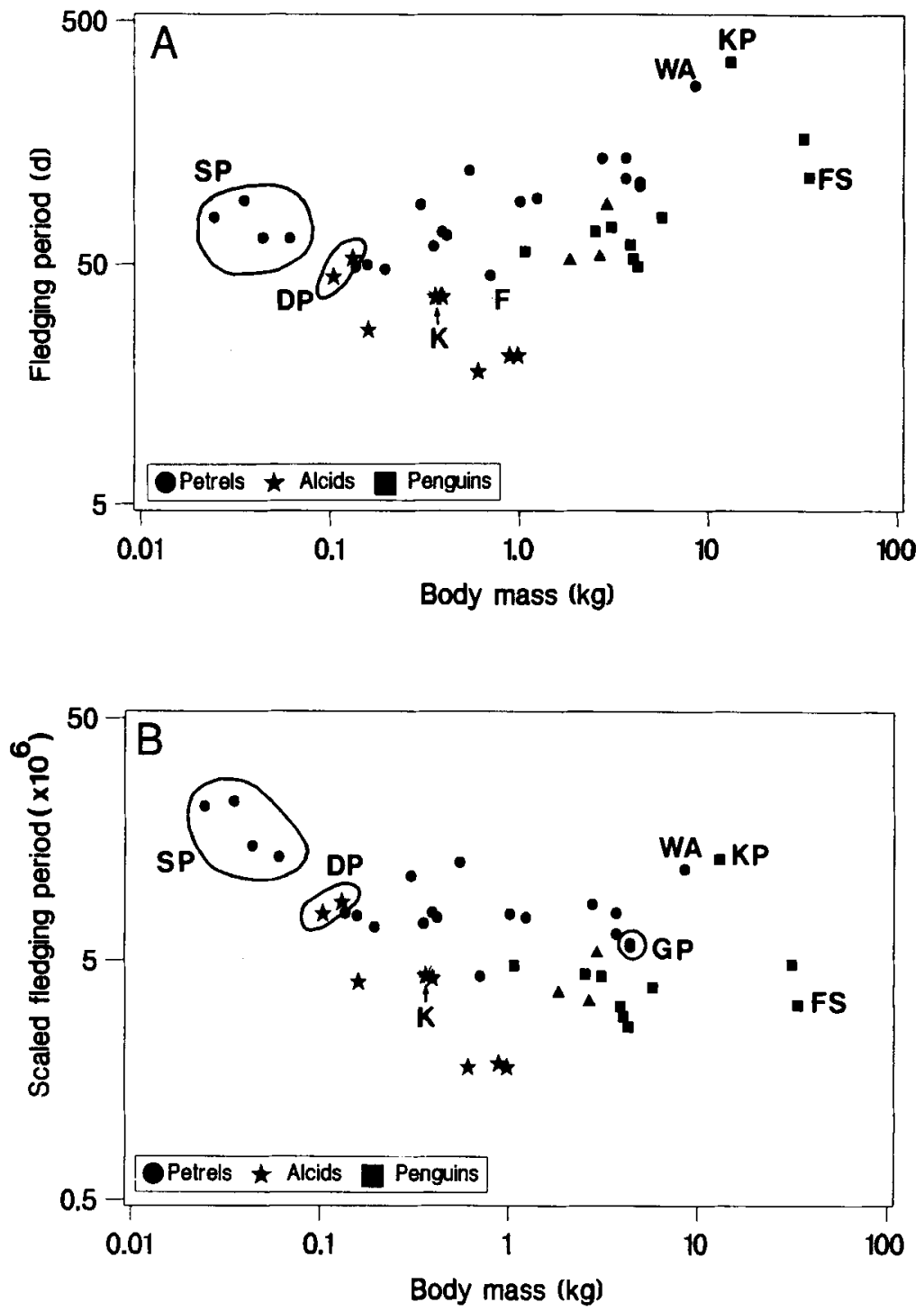

for equivalent rates of power acquisition, penguin and alcid growth rates are superior to those of petrels, which are in turn superior to those of storm-petrels.

\section{Activity and energy budgets}

Activity and energy budget data are compared on the basis of a single foraging cycle, i.e. between two successive departures on foraging trips to sea, and during the at-sea portion of this cycle. The proportionate divisions of time and energy during these two time periods are shown in Fig. 6 .
In respect of the basic foraging cycle, several generalisations can be made. For albatrosses (and probably most other Procellariformes), time ashore with their chicks after the brooding period ceases is very brief, essentially lasting the time it takes to deliver a meal. Most penguins (and Antarctic Fur Seals) spend $60-85 \%$ of a cycle at sea, the exception being the Gentoo Penguin whose single trip per day lasts only 8 hours $(33 \%)$. The remaining four species (all from the North Atlantic except the Blue-eyed Shag) brood chicks until fledging, so one parent must spend half the cycle ashore; in Blue-eyed Shags, and perhaps 

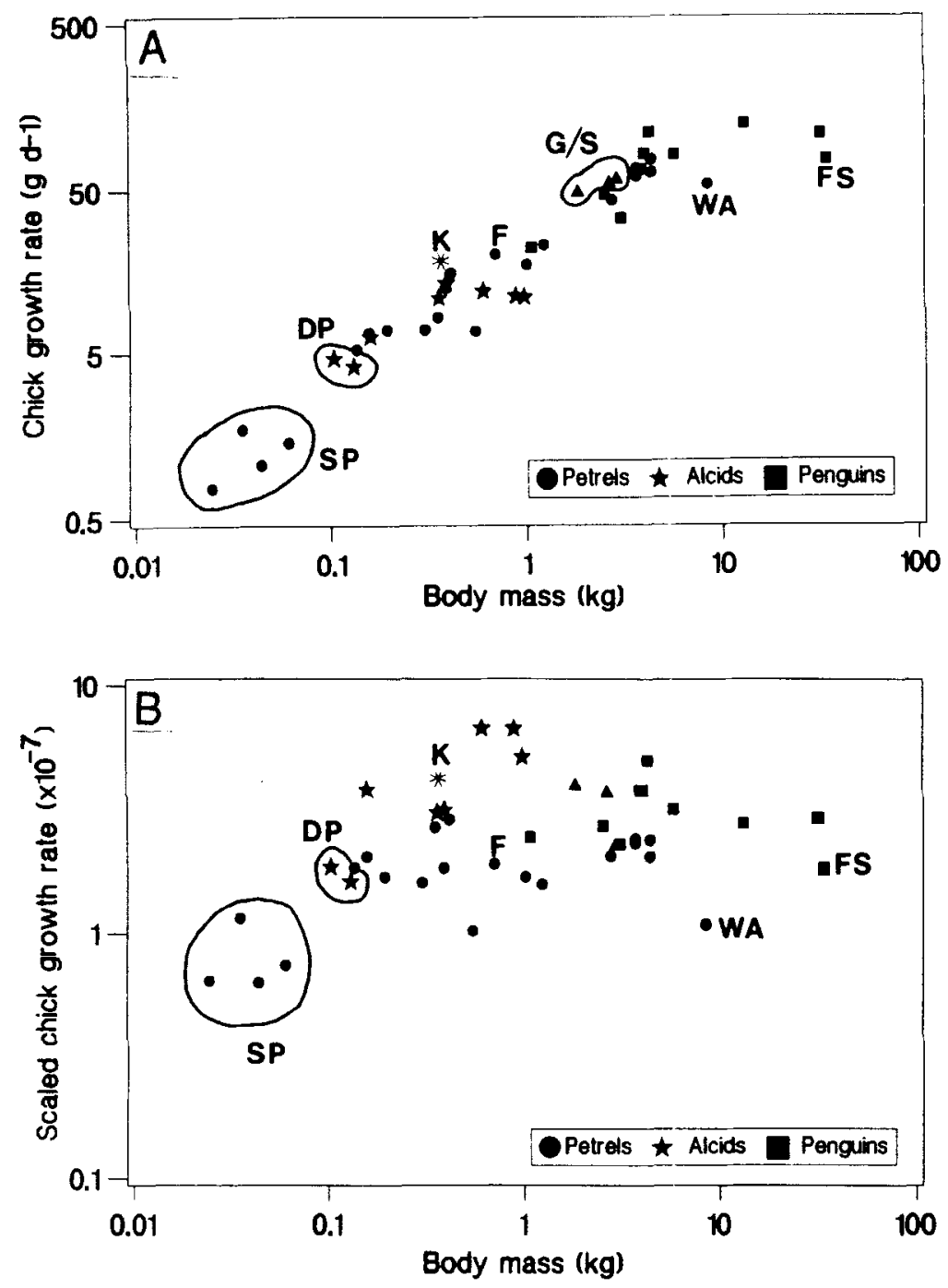

Fig. 3. Relationship between peak offspring mass and offspring (A) maximum growth rate and (B) scaled maximum growth rate. Note log-log scale. Conventions as in Fig. 1. in shags generally, considerably more than this minimum time is spent ashore.

For species that obtain their food by diving (fur seals, penguins, murres, shags), the energy costs of time at sea average 2-5 times ( $4-5$ times in all except the two largest species) costs ashore. Therefore $80-95 \%$ of the total energy budget is incurred at sea in most of these species; even those species (Gentoo Penguin, Blue-eyed Shag) which only spend one-third of a cycle at sea still incur two-thirds of their energy expenditure there. For Kittiwakes and Gannets, species which do not swim underwater, energy costs ashore are low relative to costs at sea; activity and energy budgets are, therefore, much more similar.
For most species, these high energy costs at sea are directly related to the proportion of time at sea which is spent in active foraging. Antarctic Fur Seals and the smaller penguins spend at least $80 \%$ of their time swimming and diving and even King Penguins spend more than $60 \%$ of their time doing this. Common Murres, however, appear anomalous in apparently spending $65 \%$ of their time resting and only $25 \%$ diving; the relatively high cost of flight is the main cause of their relatively high energy expenditure at sea.

In contrast, albatrosses, which spend $60-70 \%$ of their time at sea in flight, have a relatively modest increment of at-sea cost (about 125\%) over expenditure ashore since gliding flight is 
Fig. 4. Relationship between (A) fledging period and offspring maximum growth rate and (B) scaled fledging period and offspring scaled maximum growth rate. Note log-log scale. Conventions as in Fig. 1.
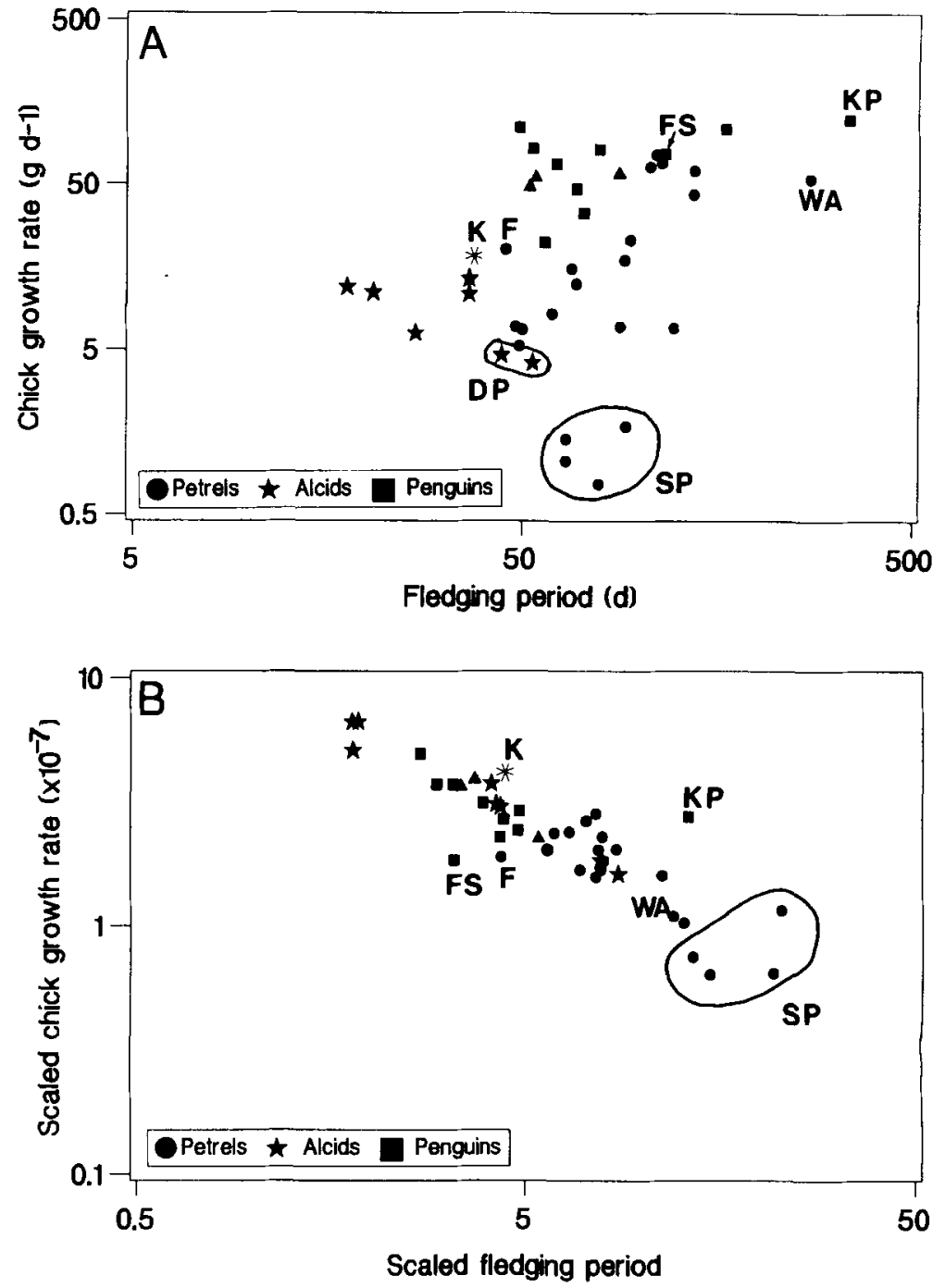

exceptionally efficient in large birds. Kittiwakes and Gannets spend about half their time at sea in flight, but the incremental cost of flight above resting is similar (c. 140\%) in both species. This low increment is partly explained by the apparently high resting costs in these species (190-490\% compared to $130-140 \%$ of BMR in albatrosses) but the flapping flight of Kittiwakes should be proportionately more expensive than the flapgliding of Gannets.

Crucial to correct interspecies comparisons of energy budgets are accurate data on active metabolic rates (Table 3 ). The results for some groups (e.g. penguins and albatrosses) are reasonably consistent between species, between the various metabolic rates, and in relation to the at-sea activity budgets; results for diving-petrels are clearly more congruent with alcids than Procellariformes, as expected on the basis of flight mode. However, the other inter- and intraspecies differences, particularly the high RMR in Gannets and low flight costs in Kittiwakes, are difficult to interpret at present. As Table 3 indicates, there is still a very slender database for assessing accurate energy budgets, particularly of at-sea activities.

\section{Foraging efficiency}

The ratio of metabolisable energy gained while 

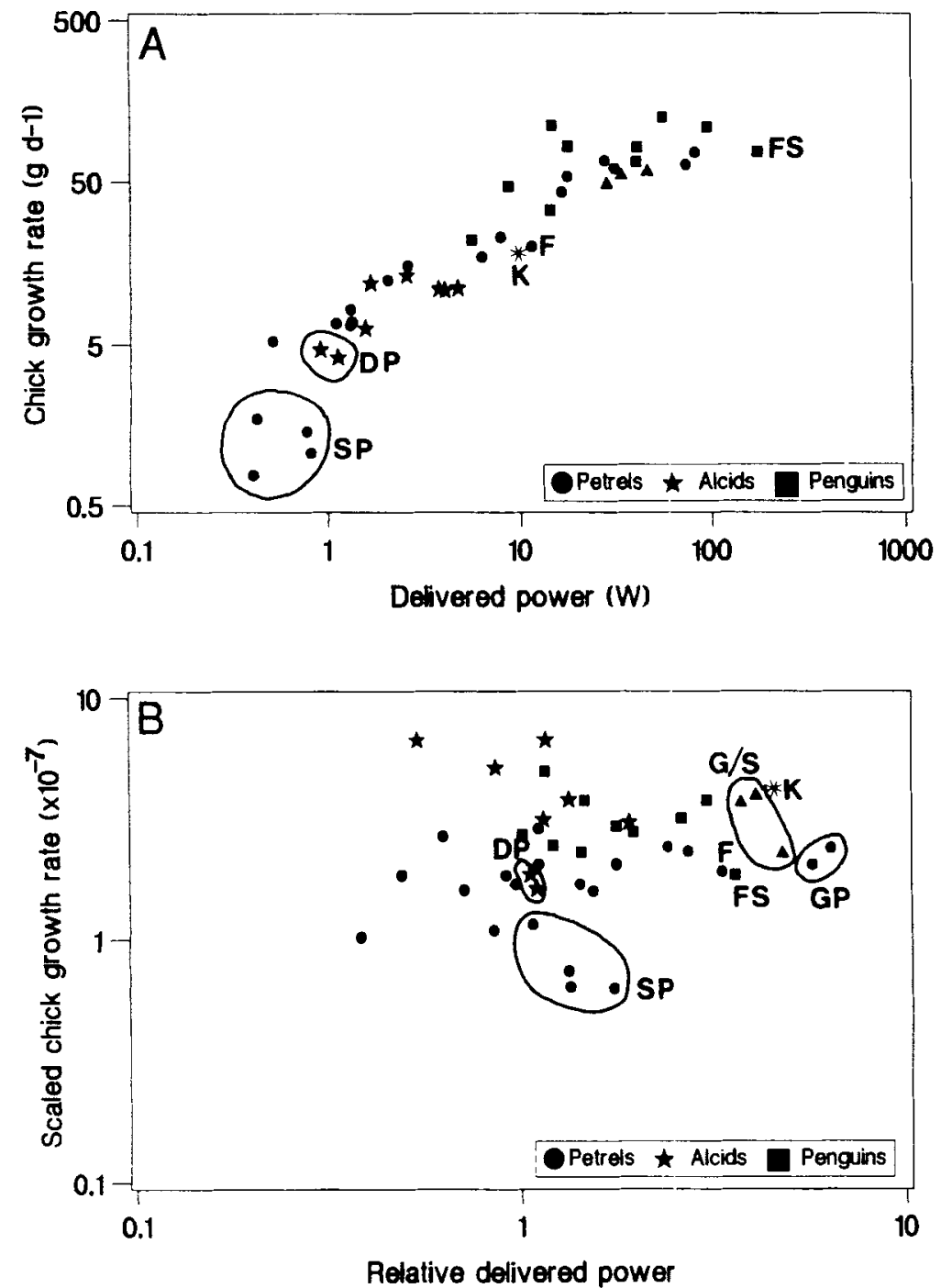

Fig. 5. Relationship between $(A)$ rate rate of energy (power) delivery per chick and offspring maximum growth and (B) relative (scaled) delivered power per chick and offspring scaled maximum chick growth rate. Note log-log scale. Conventions as in Fig. 1.

foraging (i.e. the energy required to satisfy the needs of the adult and its offspring over one complete foraging cycle) to the energy expended while foraging at sea to meet these demands was termed foraging efficiency by Nagy et al. (1984). Within the values derived from the present study (Table 4), relatively low values $(<1.5)$ seem characteristic of Procellariformes and large and small penguins, whereas high values $(>2.0)$ are shown by Kittiwakes, Blue-eyed Shags and Gentoo Penguins (all of which have broods of more than one chick) with Antarctic Fur Seal, Macaroni Penguin, Common Murre, and Gannet inter- mediate. If periods of rest are excluded, then foraging efficiency is slightly increased for albatrosses and Kittiwake, substantially increased for Gannet and Blue-eyed Shag, and greater by a factor of nearly three for Common Murre.

It should be noted that, with the kind of data currently available, species spending most of their foraging cycles at sea will inevitably tend to show lower foraging efficiencies than species spending substantial amounts of time ashore. This is unlikely to be remedied until activity-specific (e.g. resting, swimming, diving, flying) at-sea energy budgets can be calculated. 
Table 4. Foraging efficiency (ratio of metabolizable energy gained while foraging to energy used while foraging) of some North and South Atlantic seabirds (and the Antarctic fur seal).

\begin{tabular}{|c|c|c|c|c|c|}
\hline \multirow[b]{2}{*}{ Species } & \multirow{2}{*}{$\begin{array}{l}\text { Energy acquired at sea per cycle } \\
\text { to meet adult and offspring requirements }\end{array}$} & \multicolumn{2}{|c|}{$\begin{array}{l}\text { Energy expenditure at } \\
\text { sea per cycle }\end{array}$} & \multicolumn{2}{|c|}{ Foraging efficiency } \\
\hline & & Total & Active $^{1}$ & At sea & Active $^{1}$ \\
\hline Antarctic Fur seal & 207,102 & 115,154 & 112,154 & 1.80 & 1.85 \\
\hline King Penguin & 83,586 & 64,022 & - & 1.31 & - \\
\hline Gentoo Penguin & 7,876 & 2,720 & - & 2.83 & - \\
\hline Macaroni Penguin & 8,006 & 4,410 & - & 1.82 & - \\
\hline Jackass Penguin & 3,945 & 1,877 & 1.260 & 2.10 & 3.13 \\
\hline Little Penguin & 2,872 & 2,128 & - & 1.36 & - \\
\hline Wandering Albatross & 23,277 & 18,270 & 17,559 & 1.27 & 1.33 \\
\hline Grey-headed Albatross & 1,433 & 4,925 & 4,947 & 1.51 & 1.55 \\
\hline Leach's Storm-petrel & 327 & 240 & - & 1.36 & - \\
\hline Wilson's Storm-petrel & 340 & 274 & - & 1.24 & - \\
\hline Common Diving-petrel & 651 & 550 & - & 1.18 & - \\
\hline S Georgia Diving-petrel & 1,300 & 798 & 274 & 1.63 & 4.74 \\
\hline Common Murre & 4,068 & 1,711 & 1,200 & 2.38 & 3.39 \\
\hline Blue-eyed Shag & 7,162 & 3,898 & 3,235 & 1.84 & 2.21 \\
\hline Northern Gannet & 6,246 & 2,998 & 2,489 & 2.08 & 2.51 \\
\hline Black-legged Kittiwake & 2,059 & & & & \\
\hline
\end{tabular}

${ }^{1}$ Excludes periods of rest at sea.

\section{Discussion}

The major objective of this paper was to develop a framework for a coherent comparative approach to the food collecting and provisioning activities of pelagic animals. Now that such a basis has been established, this discussion will concentrate on reviewing how it can be improved.

On a broad scale this review of foraging performance is summarised in Table 5, using empirically defined, rather than subjective, criteria. The various indices generally give a reasonably congruent picture. They emphasise that storm- petrels have consistently slow rates; Gannets, shags, Kittiwakes, and to a lesser extent mediumsized penguins and fur seals, have consistently high rates; alcids and Procellariformes generally have intermediate rates.

It is obviously desirable to extend this approach to interspecies comparisons within groups, but to do this critically would require more and better data than is available now. In assembling the present data, there were few species for which complete information was readily available even for such basic parameters as mass, energy density

Table 5. Provisioning and rearing rates and foraging efficiency of different groups of seabirds (and the Antarctic fur seal).

\begin{tabular}{|c|c|c|c|c|}
\hline Group & $\begin{array}{l}\text { Relative delivered } \\
\text { power }\end{array}$ & $\begin{array}{l}\text { Scaled fledging } \\
\text { period }^{2}\end{array}$ & $\begin{array}{l}\text { Scaled growth } \\
\text { rate }^{3}\end{array}$ & $\begin{array}{l}\text { Foraging } \\
\text { efficiency }\end{array}$ \\
\hline Fur Seal & High & Short & Low & Medium \\
\hline Penguins & (Low) \& Medium & Short (-Long) & Medium (-High) & (Low-) Medium (-High) \\
\hline Alcids & Low & Short & Medium-High & Medium \\
\hline Diving-petrels & Low & Medium & Low & - \\
\hline Albatrosses & Low-Medium & Medium (-Long) & Low-Medium & Low \\
\hline Petrels & Low (-Medium) & Medium & Low (-Medium) & - \\
\hline Storm petrels & Low & Long & Low & Low \\
\hline Gannet/shags & High & Short & Medium (-High) & High \\
\hline Kittiwake & High & Short & High & High \\
\hline
\end{tabular}

\footnotetext{
${ }^{1}$ Low $=<2.0 ;$ High $=>3.5$

${ }^{2}$ Short $=<5.0 ;$ Long $=>10.0$

${ }^{3}$ Low $=<2.0 ;$ High $=>4.0$

${ }^{4}$ Low $=<1.5 ;$ High $=>2.0$
} 

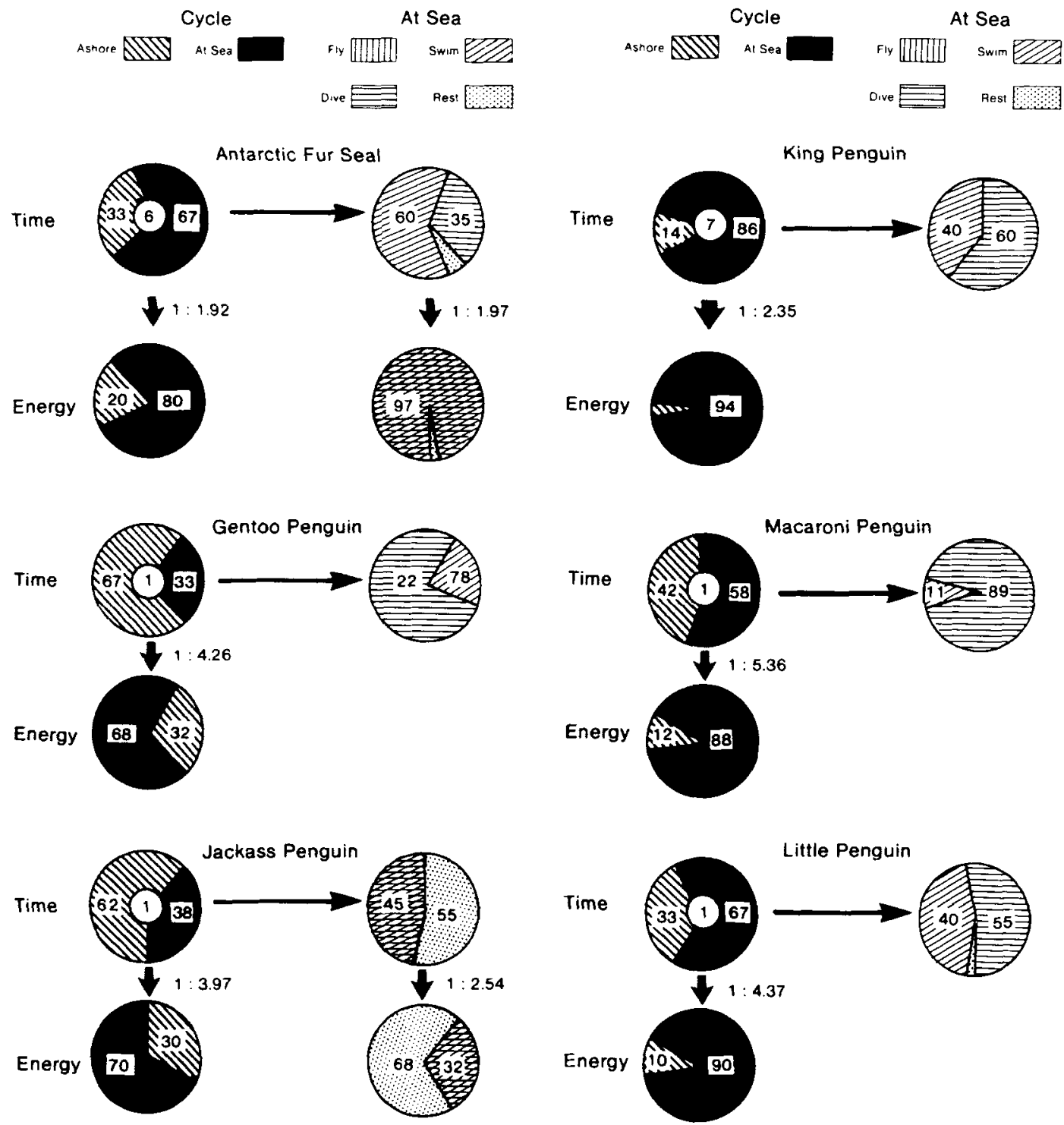

Fig. 6. Time and activity budgets, during the offspring-rearing period, for complete foraging cycles and for the at-sea portion of these. Ratios give the relative costs of time ashore versus at-sea. and for the at-sea period, of resting versus flight or swimming. Encircled central figures are the duration (days) of a complete foraging cycle.

and frequency of meals, duration of foraging trips, and chick growth rates. This was especially true of pelecaniform species. There is a disproportionate lack of data for North Atlantic species.

Eventually it will be desirable to use modified indices. Foraging efficiency and relative delivered power measure aspects of the same phenomenon. Foraging efficiency uses empirical data on adult energy budgets at sea but takes no account of the rate of delivery of meals to offspring. Delivered power, which takes the latter into account, is at present scaled using predicted rather than empirically determined metabolic rate data. When more such data are available, the rate of delivery of energy will be the more useful index. The term foraging efficiency also carries the implication that some species are better foragers than others. In reality we are dealing with species (or groups of 

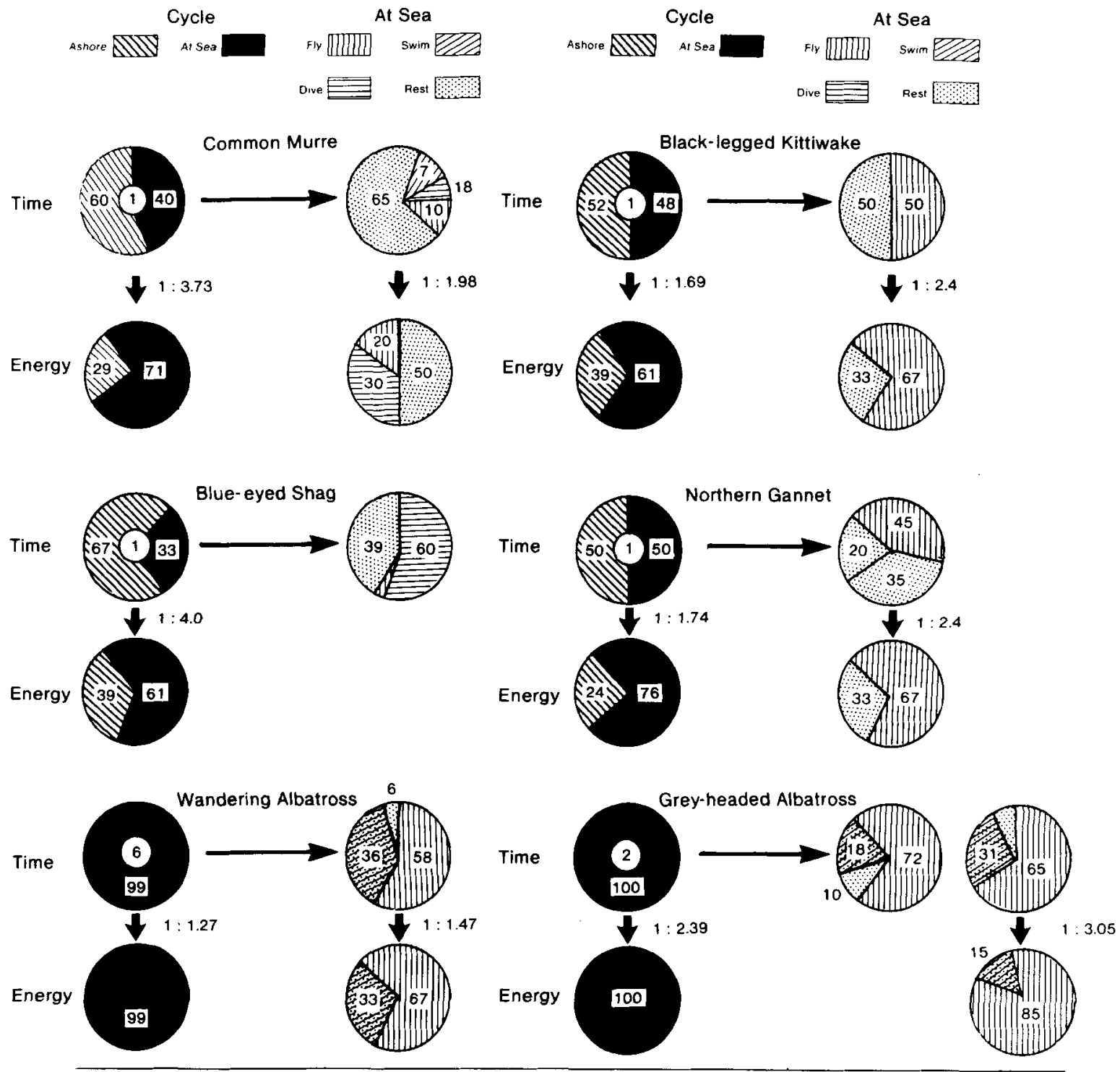

species) whose physical structure and ecological adaptations are acting in concert to shape their pattern of energy acquisition, transport, and delivery to offspring. There is a considerable history of investigation into ecological adaptations associated with this (e.g. comparisons of inshore and offshore foragers), but apart from the work by Pennycuick (1987a, b, 1989) there have been few attempts to understand the limitations imposed by physical capabilities.

The indices of offspring performance are likely to be imprecise and approximate (see above sec- tion "Rearing rate", p. 562). Although growth rate appears the most satisfactory of those investigated here, it would be preferable to use empirical data on offspring energy requirements; however to date there are only a handful of sufficiently detailed studies of chick metabolic rates.

Five years ago there were no published data on the activity and energy budgets associated with food collection by pelagic seabirds; the data summarised in Table 6 thus represent major progress. However, further significant progress, in terms of understanding the cost-benefits involved, requires 
Table 6. Time and activity budgets (\%) at sea of various seabirds (and the Antarctic fur seal).

\begin{tabular}{|c|c|c|c|c|c|c|c|}
\hline \multirow{3}{*}{$\begin{array}{l}\text { Species/ } \\
\text { Group }\end{array}$} & \multicolumn{2}{|c|}{ At sea } & \multicolumn{5}{|c|}{ Activity while at sea } \\
\hline & \multirow[b]{2}{*}{ Time } & \multirow[b]{2}{*}{ Energy } & \multicolumn{2}{|c|}{ Resting } & \multirow{2}{*}{$\frac{\text { Diving' }^{\prime}}{\text { Time }}$} & \multicolumn{2}{|c|}{ Flying } \\
\hline & & & Time & Energy & & Time & Energy \\
\hline Fur Seal & 70 & 80 & c. 5 & - & 35 & - & - \\
\hline Penguins & $60-85$ & $80-95\}$ & & & & & \\
\hline Gentoo Penguin & 30 & $80\}$ & $<10$ & & $60-90$ & - & - \\
\hline Albatrosses & 100 & 100 & $5-20 ?$ & & - & $60-70$ & $70-85$ \\
\hline Common Murre & 60 & 80 & 65 & 50 & 25 & 10 & 20 \\
\hline Gannet & 50 & 60 & 20 & & $?$ & 45 & 70 \\
\hline Kittiwake & 50 & 60 & 50 & 30 & - & 50 & 70 \\
\hline Blue-eyed Shag & 30 & 70 & $?$ & & 60 & $<5$ & - \\
\hline
\end{tabular}

${ }^{1}$ Includes average post-dive recovery time.

more precise and detailed information. Important goals for activity budgets are: 1) to improve discrimination between travelling, resting, and foraging activities; 2) to distinguish surface swimming and resting in murres, penguins, and shags; 3 ) to assess the contribution of activities other than oxygen refuelling which may occur during the interdive surface interval (Croxall et al. in 1991$)$; 4) to understand the function of time spent on the sea surface by species such as albatrosses and Gannets. (For Gannets, nighttime-on-sea is regarded as resting because they are believed not to feed at night (Birt-Friesen 1989), whereas daytime-on-sea for albatrosses is similarly believed to represent some combination of resting and scavenging rather than active foraging (Prince \& Morgan 1987)) ; 5) to distinguish between travelling and feeding flight in Kittiwakes and Gannets.

For energy budgets the principal requirement is activity-specific data. Comparisons based on field metabolic rate are particularly unsound for present purposes because the nature of the activities integrated into this energy measurement varies greatly between species.

It is obviously important to study the at-sea and onshore activities simultaneously. The commitments that adults face ashore must play a part in shaping their foraging patterns at sea; changes in provisioning rates are known to have significant effects on offspring growth and survival and the relationship between the duration and energy costs of foraging trips. The size and quality of meals delivered is obviously a crucial feature of the parent-offspring interaction in pelagic animals.
Several features of the present data, notably the close relationship between offspring growth rate and adult body mass (Fig. 3), suggest that the basic limitations on offspring growth are not the provisioning ability of adults (Lack 1968) but the capacity of offspring to cope with higher provisioning rates (Ricklefs 1983; Schaffner 1990). This is not inconsistent with the frequent reports of offspring starving through parental inability to provide sufficient food, which simply indicates that parents often fail to reach even the average maximum rate that the offspring can utilise efficiently.

It is possible, however, that small seabirds (e.g. storm-petrels) may have greater difficulty in maintaining high delivery rates, partly because of high weight-specific metabolic rates and partly because vulnerability to predators may restrict visits to one per adult per night. With large species, transporting very large masses of food may be physically difficult or uneconomic (or both) and, given the proportionately lower weight-specific energy expenditure of large birds, it may be more sensible to settle for lower provisioning and concomitant growth rates. It is obviously no coincidence that the "compromise" between flight and wing-propelled diving can only be sustained for small-tomedium-sized birds spanning about one order of magnitude of mass, whereas flying non-divers (Procellariformes) and flightless divers (penguins) span $2 \frac{1}{2}$ and $1 \frac{1}{2}$ orders, respectively. The greatest range of physiological, structural, and ecological adaptations should be available to "mediumsized" species, and the comparative study of their foraging performance should be of particular interest. 
Acknowledgements. - We thank V. B-Friesen, I. Boyd, N. Brothers, D. Cairns, G. Gabrielsen, R. Gales, M. Harris, G. Kooyman, Y. Naito, P. Prince, J. Taylor, S. Wanless, and T. Williams for answering queries and sharing their unpublished data. We thank G. Gabrielsen and T. Williams for helpful comments to the manuscript and C. J. Pennycuick for clarifying definitions of efficiency.

\section{References}

Adams, N. J. \& Brown, C. R. 1984: Metabolic rates of subAntarctic Procellariiformes: a comparative study. Comp. Biochem. Physiol. 77A, 169-173.

Adams, N. J., Brown, C. R. \& Nagy, K. A. 1986: Energy expenditure of free-ranging Wandering Albatrosses Diomedea exulans Physiol. Zool. 59, 583-591.

Barrett, R. T. \& Runde, O. J. 1980: Growth and survival of nestling Kittiwakes in Norway. Ornis Scand. 11, 228-235.

Bernstein, N. P. \& Maxson, S. J. 1984: Sexually distinct daily activity patterns of Blue-eyed Shags in Antarctica. Condor 86, 151-156.

Bernstein, N. P. \& Maxson, S. J. 1985: Reproductive energetics of Blue-eyed Shags in Antarctica. Wilson Bull. 97, 450-462.

Birt-Friesen, V. L., Montevecchi, W. A., Cairns, D. K. \& Macko, S. A. 1989: Activity-specific metabolic rates of freeliving Northern Gannets and other seabirds. Ecology 70 , 357-367.

Boyd, I. L. \& Croxall, J. P. 1992: Diving behaviour of lactating Antarctic fur seals Arctocephalus gazella at South Georgia. Canadian Journal of Zoology. In press.

Brooke, M de L. 1990: The Manx Shearwater. T. D. \& A. Poyser \& Academic Press, London.

Brown, C. R. \& Adams, N. J. 1984: Basal metabolic rate and energy cost of incubation in the Wandering Albatross Diomedea exulans. Condor 86, 182-186.

Burger, A. E \& Piatt, J. L. 1990: Flexible time budgets in breeding Common Murres: buffers against variable prey abundance. Stud. Avian. Biol. 14, 71-83.

Cairns, D. K., Bredin, K. A., \& Montevecchi, W. A. 1987: Activity budgets and foraging ranges of breeding Common Murres. Auk 104, 218-224.

Cairns, D. K., Montevecchi, W. A., Birt-Friesen, V. L. \& Macko, S. A. 1990: Energy expenditures, activity budgets, and prey harvest of breeding Common Murres. Stud. Avian Biol. 14, 84-92.

Costa, D. P. \& Prince, P. A. 1987: Foraging energetics of Greyheaded Albatrosses Diomedea chrysostoma at Bird Island, South Georgia. Ibis 129, 190-196.

Costa, D. P., Croxall. J. P. \& Duck, C. 1989: Foraging energetics of Antarctic Fur Seals in relation to changes in prey availability. Ecology 70, 596-606.

Cramp, S. \& Simmons, K. E. L. 1977: The birds of the Western Palearctic, 1. Oxford Univ. Press, Oxford.

Cramp, S. \& Simmons, K. E. L. 1983: The birds of the Western Palearctic, 3. Oxford Univ. Press, Oxford.

Croxall, J. P. 1984: Seabirds. Pp. 533-616 in Laws, R.M. (ed.): Antarctic ecology, 2. Academic Press, London.

Croxall, J. P. \& Gaston, A. J. 1988: Patterns of reproduction in high latitude northern and southern hemisphere seabirds. Pp. 1176-1194 in Ovellett, H. (ed.): Acta XIX Congressus Internationalis Ornithologici. Congress. Univ. Ottawa Press, Ottawa.
Croxall, J. P., Everson, I., Kooyman, G. L., Ricketts, C. \& Davis, R. W. 1985: Fur seal diving behaviour in relation to vertical distribution of krill. J. Anim. Ecol. 54, 1-8.

Croxall, J. P., Hill, H. J., Lidstone-Scott, R., O'Connell, M. J. \& Prince, P. A. 1988a: Food and feeding ecology of Wilson's Storm Petrel Oceanites oceanicus at South Georgia. J. Zool. Lond. 216, 83-102.

Croxall, J. P., McCann, T. S., Prince, P. A. \& Rothery, P. 1988b: Reproductive performance of seabirds and seals at South Georgia and Signy Island, South Orkney Islands 1976-1986: Implications for Southern ocean monitoring studies. Pp. 261-285 in Sahrhage, D. (ed.): Antarctic Ocean and Resources Variability. Springer Verlag, Berlin.

Croxall, J. P., Naito, Y., Kato, A., Rothery, P. \& Briggs, D. R. 1991: Diving patterns and performance in the Antarctic Blue-eyed Shag Phalacrocorax atriceps J. Zool. Lond. 225, 177-199.

Croxall, J. P., Briggs, D. R., Kato, A., Naito, Y., Watanuki, Y. \& Williams, T. D. 1992: Diving pattern and performance in the macaroni penguin Eudyptes chrysolophus. Journal of Zoology. In press.

Davis, R. W., Croxall, J. P. \& O'Connell, M. J. 1989: The reproductive energetics of Gentoo and Macaroni Penguins at South Georgia. J. Anim. Ecol. 58, 59-74.

Drent, R. H. \& Daan, S. 1980: The prudent parent: energetic adjustments in avian breeding. Ardea 68, 225-252.

Ellis, H. I. 1984: Energetics of free-ranging seabirds. Pp. 204-234 in Whittow, G. C. \& Rahn, H. (eds.): Seabird energetics. Plenum, New York.

Furness, R. W. \& Todd, C. M. 1984: Diets and feeding of Fulmars Fulmarus glacialis during the breeding season: a comparison between St Kilda and Shetland colonies. Ibis 126, 379-387.

Gabrielsen, G. W., Mehlum, F. \& Nagy, K. A. 1987: Daily energy expenditure and energy utilisation of free-ranging Black-legged Kittiwakes. Condor 89, 126-132.

Gabrielsen, G. W. \& Mehlum, F, 1989: Kittiwake activity monitored by telemetry. Pp. 421-429 in Amlaner, C. J. (ed.): Biotelemetry X, Proc Tenth Int. Symp. Biotelemetry. Univ. Arkansas Press, Fayetteville \& London.

Gabrielsen, G. W., Mehlum, F. \& Karlsen, H. E. 1988: Thermoregulation in four species of arctic seabirds. J. Comp. Physiol. B157, 703-708.

Galbraith, H. 1983: The diet and feeding ecology of breeding Kittiwakes Rissa tridactyla. Bird Study 30, 109-120.

Gales, R. \& Green, B. 1990: The annual energetics cycle of Little Penguins Eudyptula minor. Ecology 71, 2297-2312.

Gales, R., Williams, C. \& Ritz, D. 1990: Foraging behaviour of the Little Penguin Eudyptula minor: initial results and assessment of instrument effect. J. Zool. Lond. 220, 61-85.

Green, B. \& Brothers, N. 1989: Water and sodium turnover and estimated food consumption rates in free-living Fairy Prions Pachyptila turtur and Common Diving-petrels Pelecanoides urinatrix. Physiol. Zool. 62, 702-715.

Hunter, S. 1983: The food and feeding ecology of the giant petrels Macronectes halli and M. giganteus at South Georgia. J. Zool. Lond. 200, 521-538.

Kooyman, G. L., Davis, R. W. \& Croxall, J. P. 1986: Diving behaviour of the Antarctic fur seal Arctocephalus gazella. Pp. 115-125 in Gentry, R. L. \& Kooyman, G. L. (eds.): Fur Seals: maternal strategies on land and at sea. Princeton Univ. Press, Princeton.

Kooyman, G. L., Cherel, Y., Le Maho, Y., Croxall, J. P., Thorson, P. H., Ridoux, V. \& Kooyman, C. A. 1992: Diving 
behavior and energetics during foraging cycles in king penguins. Ecological Monographs. 62. 143-163.

Lack, D. 1968. Ecological adaptations for breeding in birds. Methuen, London.

Montevecchi, W. A. \& Porter, J. M. 1980: Parental investments by seabirds at the breeding area with emphasis on Northern Gannets, Morus bassanus. Pp. 323-365 in Burger, J., Olla, B. L. \& Winn, H. E. (eds.): Behaviour of marine animals, IV. Plenum, New York.

Nagy, K. A. 1987: Field metabolic rate and food requirement scaling in mammals and birds. Ecol. Monogr. 57, 111-128.

Nagy, K. A., Siegfried, W. R. \& Wilson, R. P. 1984: Energy utilisation by free-ranging Jackass Penguins, Spheniscus demersus. Ecology 65, 1648-1655.

Nelson, J. B. 1978: The Sulidae. Oxford Univ. Press, Edinburgh.

Nettleship, D. N. \& Birkhead. T. R. 1985: The Allantic Alcidae. Academic Press, Orlando.

Obst, B. S. Nagy, K. A. \& Ricklefs, R. E. 1987: Energy utilization in Wilson's Storm-petrel (Oceanites oceanicus). Physiol. Zool. 60, 200-210.

Pennycuick, C. J. 1987a: Flight of auks (Alcidae) and other northem seabirds compared with southern Procellariformes: ornithodolite observations. J. Exp. Biol. 128, 335-347.

Pennycuick, C. J. 1987b: Flight of seabirds. Pp. 43-62 in Croxall, J. P. (ed.): Seabirds feeding ecology and role in marine ecosystems. Cambridge Univ. Press, Cambridge.

Pennycuick, C. J. 1989: Bird flight performance. A pracrical calculation manual Oxford Univ. Press, Oxford.

Pennycuick, C. J., Croxall, J. P. \& Prince, P. A. 1984: Scaling of foraging radius and growth rate in petrels and albatrosses (Procellariiformes). Ornis Scand. 15, 145-154.

Prince, P. A. \& Francis, M. D. 1984: Activity budgets of foraging Grey-headed Albatrosses. Condor 86, 297-300.
Prince, P. A. \& Harris, M. P. 1988: Food and feeding ecology of alcids and penguins. Pp. 1195-1204 in Ovellett, H. (ed.): Acta XIX Congress Internationalis Ornithologici. Congress Univ. Ottawa Press, Ottawa.

Prince, P. A. \& Morgan, R. A. 1987: Diet and feeding ecology of Procellariiformes. Pp. 135-171 in Croxall, J. P. (ed.): Seabirds: Feeding ecology and role in marine ecosystems. Cambridge Univ. Press, Cambridge.

Ricklefs, R. E. 1968: Patterns of growth in birds. Ibis 110, 419-451.

Ricklefs, R. E. 1983: Some considerations of the reproductive energetics of pelagic seabirds. Stud. Avian Biol. 8, 84-94.

Ricklefs, R. E. \& Matthew, K. K. 1983: Rates of oxygen consumption in four species of seabird at Palmer Station, Antarctic Peninsula. Comp. Biochem. Physiol. 74A, 885-888.

Ricklefs, R. E., Roby, D. D. \& Williams, J. B. 1986: Daily energy expenditure of adult Leach's Storm-petrels during the nesting cycle. Physiol. Zool. 59. 649-660.

Roby, D. D., \& Ricklefs, R. E. 1986: Energy expenditure in adult Least Auklets and diving-petrels during the chickrearing period. Physiol. Zool. 59, 661-678.

Schaffner, F. C. 1990: Food provisioning by White-tailed Tropicbirds: effects on the developmental pattern of chicks. Ecology 71, 375-390.

Shaw, P. 1984: Factors affecting the breeding performance of the Antarctic Blue-eyed Shag (Phalacrocorax atriceps bransfieldensis) Ph.D. thesis, Univ, of Durham.

Wanless, S. Burger, A. E. \& Harris, M. P. 1991: Diving depths of Shags Phalacrocorax atriceps breeding on the Isle of May. Ibis. 133, 37-42.

Williams, T. D., Briggs. D. R., Croxall, J. P., Naito, Y. \& Kato, A. 1992: Diving pattern and performance in relation to foraging ecology in the gentoo penguin Pygoscelis papua Journal of Zoology. In press. 


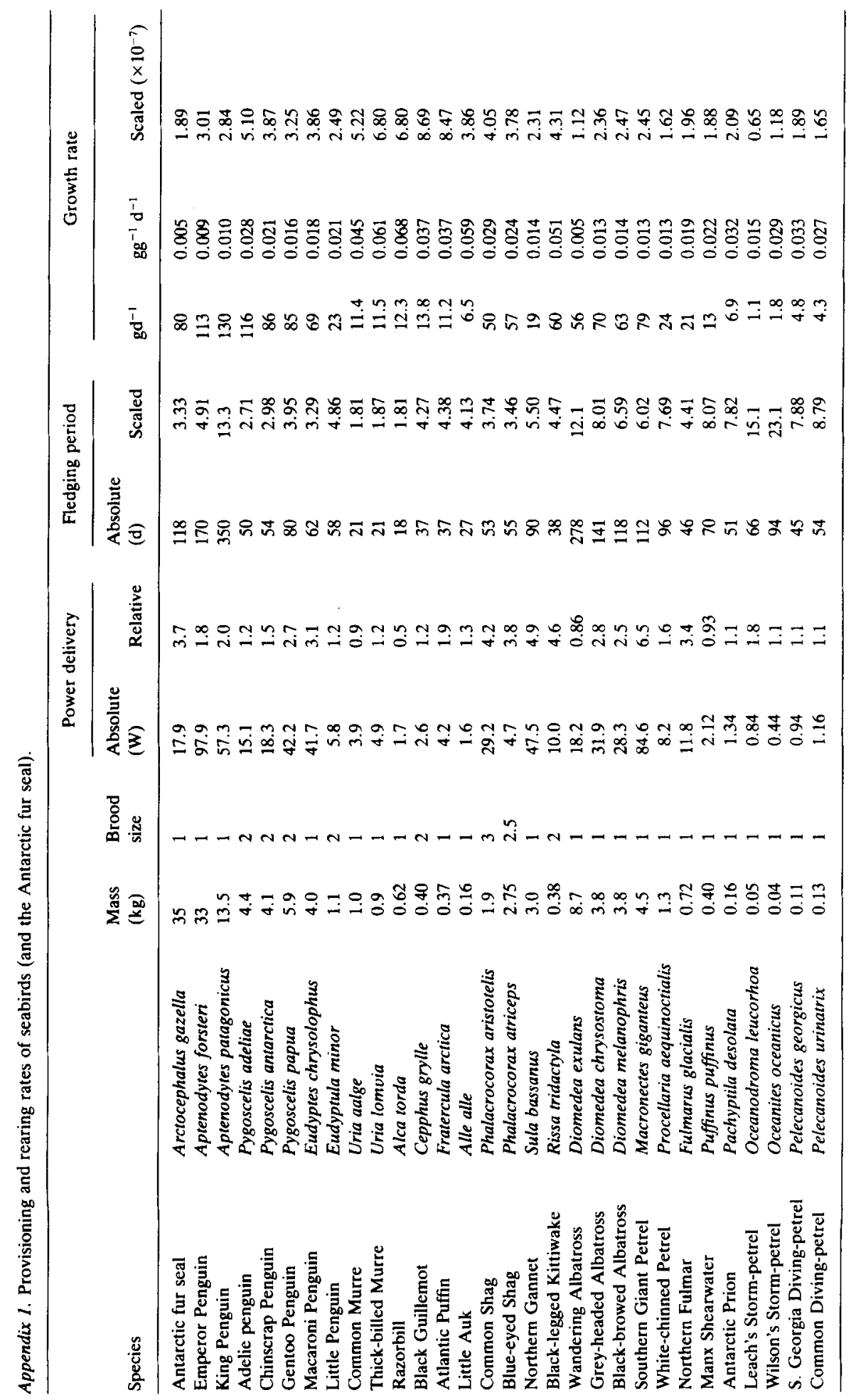


Appendix 2. Energy and activity budgets of seabirds (and the Antarctic fur seal) during foraging cycles.

\begin{tabular}{|c|c|c|c|c|c|c|c|c|}
\hline \multirow[b]{2}{*}{ Species } & \multirow[b]{2}{*}{ Mass } & \multirow{2}{*}{$\begin{array}{l}\text { Cycle } \\
\text { (d) }\end{array}$} & \multirow{2}{*}{$\begin{array}{l}\% \text { Cycle } \\
\text { ashore }\end{array}$} & \multicolumn{3}{|c|}{ Expenditure ashore } & \multirow{2}{*}{$\begin{array}{l}\% \text { Cycle } \\
\text { at sea }\end{array}$} & \multirow{2}{*}{$\begin{array}{l}\text { Fly/ } \\
\text { Swim }(\%)\end{array}$} \\
\hline & & & & $W$ & kJ & $\%$ cycle & & \\
\hline Antarctic Fur Seal & 35 & 6 & 33 & 174 & 29,998 & 20.7 & 67 & 60 \\
\hline King Penguin & 13 & 7 & 14 & 52.7 & 4.549 & 6.6 & 86 & 40 \\
\hline Gentoo Penguin & 5.8 & 1 & 67 & 22.8 & 1,320 & 32.7 & 33 & \\
\hline Macaroni Penguin & 4.0 & 1 & 42 & 16.4 & 595 & 11.9 & 58 & \\
\hline Jackass Penguin & 3.2 & 1 & 63 & 14.6 & 788 & 29.6 & 37 & 45 \\
\hline Little Penguin & 1.1 & 1 & 33 & 8.42 & 240 & 10.0 & 67 & 40 \\
\hline Wandering Albatross & 8.7 & 6 & 1 & 28.0 & 242 & 1.3 & 99 & 58 \\
\hline Grey-headed Albatross & 3.8 & 2 & $<1$ & 11.9 & & 0 & 100 & 65 \\
\hline Leach's Storm-petrel & 0.05 & 2 & 2 & 0.60 & 2.1 & 1 & 98 & \\
\hline Wilson's Storm-petrel & 0.04 & 2 & 2 & 0.83 & 2.9 & 1 & 98 & 100 \\
\hline Common Diving-petrel & 1.13 & 1 & $>1$ & 1.48 & & 0 & 100 & \\
\hline S. Georgia Diving-petrel & 0.10 & 1 & $>1$ & 1.30 & & 0 & 100 & \\
\hline Common Murre & 1.0 & 1 & 51 & 6.19 & 273 & 21.8 & 49 & 10 \\
\hline Blue-eyed Shag & 2.8 & 1 & 67 & 14.8 & 857 & 33.3 & 33 & 1 \\
\hline \multirow[t]{2}{*}{ Northern Gannet ${ }^{2}$} & 3.0 & 1 & 35 & 40.0 & 1,210 & 23.7 & 65 & 45 \\
\hline & & & 50 & 40.0 & 1.728 & 36.6 & 50 & \\
\hline Black-legged Kittiwake & 0.4 & 2 & 52 & 6.91 & 621 & 39.0 & 48 & 50 \\
\hline
\end{tabular}

${ }^{1}$ In flying birds and penguins, respectively.

${ }^{2}$ First line uses empirical data on attendance ashore (Birt-Friesen pers. comm.); second line assumes sexes share duties equally (for more realistic comparison with other species).

Appendix 2. Continued.

\begin{tabular}{|c|c|c|c|c|c|c|c|}
\hline \multirow{2}{*}{$\begin{array}{l}\text { Dive } \\
(\%)\end{array}$} & \multirow{2}{*}{$\begin{array}{l}\text { Rest } \\
(\%)\end{array}$} & \multicolumn{3}{|c|}{ Expenditure at sea } & \multirow{2}{*}{$\begin{array}{l}\text { Expenditure } \\
\text { per cycle (kJ) }\end{array}$} & \multirow{2}{*}{$\begin{array}{l}\text { Offspring } \\
\text { per cycle }(k J)\end{array}$} & \multirow{2}{*}{$\begin{array}{l}\text { Total } \\
(\mathrm{kJ})\end{array}$} \\
\hline & & w & $\mathrm{kJ}$ & $\%$ cycle & & & \\
\hline 35 & 5 & 333 & 115,154 & 79.3 & 145,152 & 61,950 & 207,102 \\
\hline \multirow[t]{3}{*}{60} & $?$ & 124 & 64,022 & 93.4 & 68,570 & 15,015 & 83,586 \\
\hline & & 95.4 & 2,720 & 67.3 & 4,040 & 3.646 & 7,876 \\
\hline & & 88.0 & 4,410 & 88.1 & 5,005 & 3,001 & 8,006 \\
\hline 45 & 55 & 57.9 & 1,877 & 70.4 & 2.665 & 1,280 & 3,945 \\
\hline 55 & 5 & 36.8 & 2.128 & 90.0 & 2,368 & 504 & 2,872 \\
\hline 36 & 6 & 35.6 & 18,270 & 98.7 & 18.512 & 4,765 & 23,277 \\
\hline \multirow[t]{5}{*}{31} & 4 & 28.5 & 4,925 & 100 & 4,925 & 2,508 & 1,433 \\
\hline & & 1.42 & 240 & 99 & 242 & 85 & 327 \\
\hline & & 1.62 & 274 & 99 & 274 & 66 & 340 \\
\hline & & 6.37 & 550 & 100 & 550 & 111 & 651 \\
\hline & & 5.25 & 454 & 100 & 454 & 101 & 555 \\
\hline 18 & 72 & 23.1 & 978 & 78.2 & 1.251 & 181 & 1,432 \\
\hline 60 & 39 & 60.0 & 1,711 & 66.7 & 2,568 & 1,500 & 4,068 \\
\hline \multirow[t]{2}{*}{35} & 20 & 69.4 & 3,998 & 76.3 & 5,108 & 2,054 & 7,162 \\
\hline & & & 2,998 & 63.4 & 4,726 & 1,520 & 6,246 \\
\hline 50 & 50 & 11.7 & 970 & 61.0 & 1,591 & 468 & 2,059 \\
\hline
\end{tabular}

